\title{
Soil Moisture and Plant Canopy Temperature Sensing for Irrigation Application in Cotton
}

\author{
Ruixiu Sui ${ }^{1}$, Daniel K. Fisher ${ }^{1} \&$ Edward M. Barnes ${ }^{2}$ \\ ${ }^{1}$ USDA-ARS, Crop Production Systems Research Unit, Stoneville, MS 38776, USA \\ ${ }^{2}$ Cotton Incorporated, Cary, NC 27513, USA \\ Correspondence: Ruixiu Sui, USDA-ARS, Crop Production Systems Research Unit, Stoneville, MS 38776, USA. \\ Tel: 1-662-686-5382. E-mail: ruixiu.sui@ars.usda.gov
}

\author{
Received: August 10, 2012 Accepted: August 27, 2012 Online Published: November 15, 2012 \\ doi:10.5539/jas.v4n12p93 \\ URL: http://dx.doi.org/10.5539/jas.v4n12p93
}

\begin{abstract}
There is a need to provide technical tools to cotton producers for appropriate management of irrigation in the Mid-South region of the U.S.A wireless sensor network was deployed in a cotton field to monitor soil water status for irrigation. The network included two systems, a Decagon system and a microcontroller-based system. The Decagon system consisted of soil volumetric water-content sensors, wireless data loggers, and a central data station. Sensor data collected by each data logger were wirelessly transferred to and stored in the data station. The microcontroller-based system was designed to be a low-cost data logger for monitoring Watermark water-potential sensors. An infrared thermometer was used in the field to measure plant canopy temperature for evaluating its usefulness in detecting water stress in cotton under humid conditions. Soil water and plant canopy temperature data were collected during the 2011 cotton growing season. Results indicated that the soil water sensors were able to measure the soil water status, and the measurements recorded by the systems reflected general trends of soil water change during the growing season. Soil water content decreased at a higher rate in $15-\mathrm{cm}$ and $30-\mathrm{cm}$ depths than in $60-\mathrm{cm}$ depth before 60 days after planting. A sharp decrease of soil water content in $60-\mathrm{cm}$ depth was observed from 60 to 80 days after planting. Sensor measurements responded to effects of soil texture on available water capacity. Canopy temperature of non-irrigated plants is 2-4 $\mathrm{C}$ higher than that of the irrigated plants during peak time of day. Supplemental irrigation increased yield by $14.2 \%$ in this study. System installation and maintenance procedures developed worked well in general. Some installation and operational issues were found and need to be resolved for wider field operation and user acceptance.
\end{abstract}

Keywords: wireless sensor network, soil moisture, irrigation, canopy temperature, cotton

\section{Introduction}

Uncertainty in the amount and timing of precipitation is one of the most serious risks to cotton producers in the Mid-South area of the U.S., and highly variable soil textural characteristics of the region require careful irrigation planning. In recent years, the producers have become increasingly reliant on supplemental irrigation to ensure adequate yields and reduce risks of production, but very few use any irrigation scheduling aids. There is a need to provide technical tools to the producers for appropriate management of irrigation in the region.

\subsection{Literature Review}

Soil water sensing. Timely and accurate determination of temporal and spatial plant and soil water status is essential for proper scheduling of irrigations. In order to increase water use efficiency and productivity, novel sensing technologies are required to determine crop water status and conduct irrigation scheduling. Crop water status and the amount of supplementary water needed can be assessed by measuring soil moisture and plant physical response to water stress. Various types of sensing devices have been developed and made commercially available for water management applications, including sensors for measuring volumetric water content and soil-water potential. R. Yoder, Johnson, Wilkerson, and D. Yoder (1997) tested 23 soil water sensors representing eight sensor types, including neutron probe, electrical capacitance, electrical resistance, TDR (time domain reflectometry), and heat dissipation with carefully controlled soil water contents. Measurement errors of the volumetric water content of the soil were determined for each sensor. The results indicated that the capacitance sensors had the best performance in the study. Leib, Jabro, and Matthews (2003) evaluated soil moisture sensors 
of several different brands and types under identical operating conditions in the field for three years. They found that most sensors were able to follow the general trends of soil water or potential changes during the growing season, but that actual measured values varied significantly between sensors and calibrated neutron probe measurements. It was suggested that a soil specific calibration of each sensor was necessary to obtain high accuracy in the measurements. Evett, Tolk, and Howell (2006) compared several EM (electromagnetic) sensors with a neutron moisture meter in measuring water content of three soils. It was found that all EM sensing devices exhibited estimation precision better than $0.01 \mathrm{~m}^{3} \mathrm{~m}^{-3}$ under isothermal conditions. However, under non-isothermal conditions, the test showed that all of the sensors were sensitive to soil temperature differences. Similar to the suggestion by Leib et al. (2003), the authors recommended that all EM sensing devices would require separate calibrations for different soil horizons. EM sensors were inexpensive, easy to install and maintain, and able to provide reliable information for irrigation scheduling and control, but must be well-calibrated under specific operational conditions including soil type and temperature.

Automated data acquisition. Rapid advances in electronic technology have resulted in a variety of new sensing, monitoring, and control capabilities. These current and rapidly evolving technologies can be adapted to provide the high level of monitoring and control capability that is needed to address information requirements for agriculture and water management. While many different types of data-collection instruments and sensors are commercially available, features, capabilities, and prices can vary greatly. Inexpensive solid-state sensors, microprocessors, and auxiliary components are also available for use in developing inexpensive, custom-designed monitoring systems (Moody, Wilkerson, Hart, \& Sewell, 2004; Noordin, Onn, \& Ismail, 2006; Fisher, 2007; Vellidis, Tucker, Perry, Kvien, \& Bednarz, 2008; Fisher \& Kebede, 2010).

Wireless sensor networks (WSNs) offer the capability of providing continuous, real-time, in-situ measurements under a variety of operating conditions. Recent advances in WSNs and internet communication technologies offer tremendous opportunities for development and application of sensor systems for agriculture (N. Wang, Zhang, \& M. Wang, 2006; Pierce \& Elliott, 2008; Kitchen, 2008). Research has been conducted on using wireless systems for irrigation scheduling and automation (Harms, 2005; King, R. Wall, \& L. Wall, 2005; Pierce \& Elliott, 2008; Lea-Cox, Ristvey, Ross, \& Kantor, 2009). Kim, Evans, and Iversen (2009) integrated a controllable irrigation system with a WSN for automated variable-rate irrigation in which soil moisture sensors installed in the field were remotely monitored by a base station, allowing irrigation decisions to be made site-specifically. Vellidis et al. (2008) developed and evaluated a wireless smart sensor array for irrigation scheduling in cotton. The wireless sensor system monitored soil water status and soil and air temperature during the growing season, and data collected by the system were successfully used for scheduling irrigation. O'Shaughnessy and Evett (2010) compared the performance of mesh and non-mesh WSNs located on a center pivot lateral and in the irrigated field below the center pivot system and observed that wireless mesh-networking sensors could function on a moving sprinkler irrigation system. Expanding cellular communications infrastructure is further increasing data-transmission options, making monitoring from very remote locations possible and affordable. Cellular communications, in conjunction with the Internet, are revolutionizing the transmission of and access to information.

\subsection{Objectives}

The objectives of this study were to 1) develop a method for installation and maintenance of a wireless sensor system for soil moisture measurement, 2) conduct field evaluations of the performance of the soil sensor measurement systems; and 3) measure plant canopy temperature in a cotton field.

\section{Materials and Methods}

\subsection{Experimental Site}

A 10-ha cotton field at the Jamie Whitten Delta States Research Center, Stoneville, MS USA (latitude: $33^{\circ} 26^{\prime} 30.86^{\prime \prime}$, longitude: $\left.-90^{\circ} 53^{\prime} 26.60^{\prime \prime}\right)$ was selected as an experimental site. The field was split into irrigated and non-irrigated treatments. Within each treatment, plots were laid out in a complete randomized block design (CRBD) with six nitrogen $(\mathrm{N})$ application rates $(0,39,67,101,135$, and $168 \mathrm{~kg} / \mathrm{ha}$ ) and four replications (Figure 1). One soil samplew as collected from each plot, and the samples were analyzed for soil texture at Soil Testing Laboratory of Mississippi State University. Soil texture in the field varied from silt to silt loam (Table 1).

\subsection{System Description}

Two systems were used to measure and record soil water status, one consisting of sensors and data loggers from Decagon Devices, and the other using Watermark sensors and microprocessor-based data acquisition units. Infrared thermometers were used to measure plant canopy temperature in the field. 
Decagon system. Decagon systems used in this study include soil water-content sensors, wireless data loggers, and a wireless data station (Decagon Devices, Inc., Pullman, WA). Two types of soil water-content sensors were used; models EC-5 and 5TM. The EC-5 sensor measured soil volumetric water content only, while the 5TM sensor measured both water content and soil temperature. EM50R and EM50G data loggers were used to collect data from the sensors. The EM50R was a radio data logger, which wirelessly transmitted data to a data station on the $900-\mathrm{MHz}$ frequency and had 1 Megabytes of internal memory for data storage. The EM50G logger transmitted data through a cellular communication network to a service which made data wirelessly received from the EM50G logger available on the internet. Each data logger (EM50R and EM50G) had the capacity to collect data from up to 5 sensors. The data station was employed to receive and store the data that were sent by EM50R loggers. Data stored in the data station were downloaded in the field via its serial port to a laptop computer for processing.

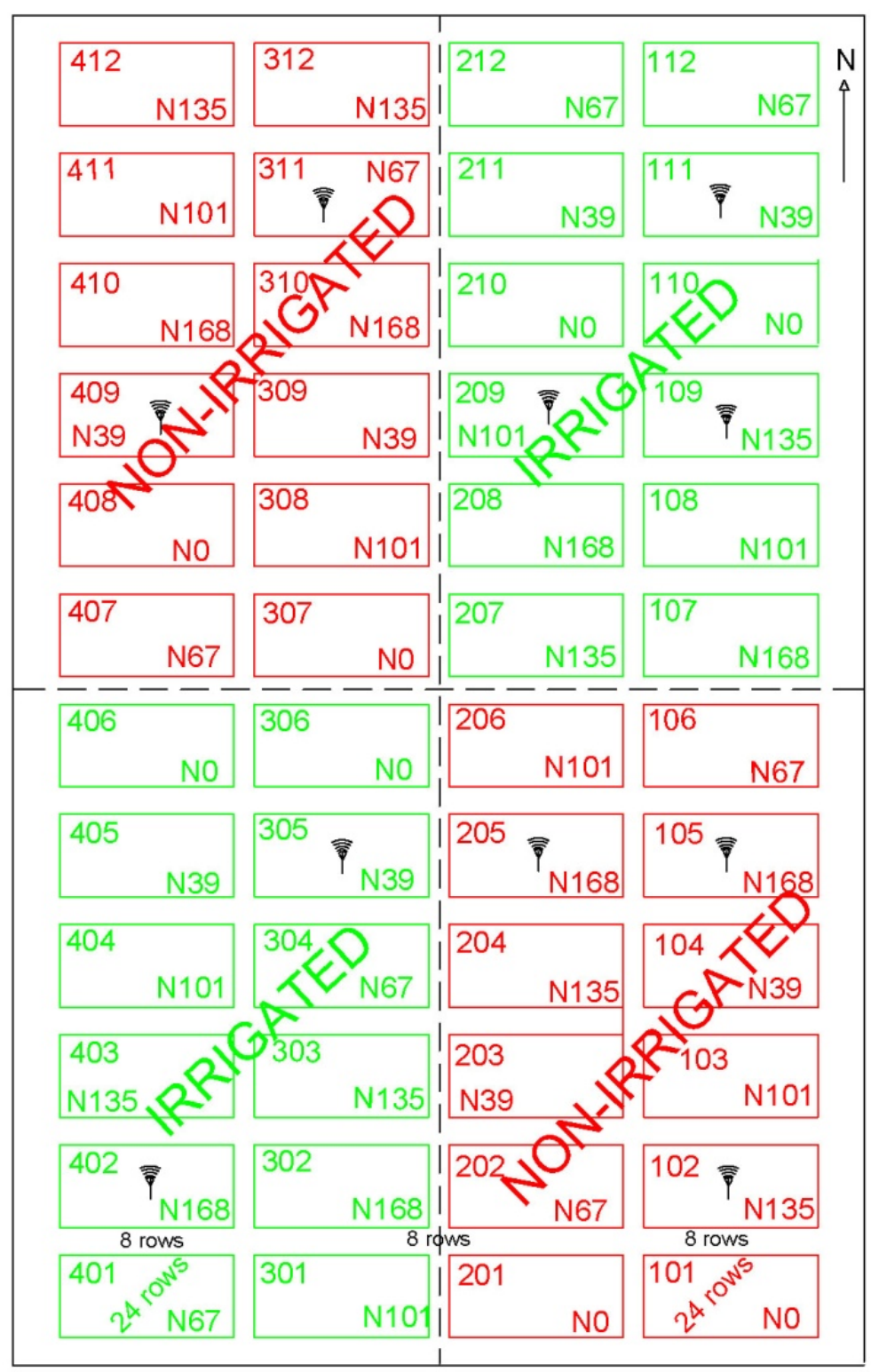

Figure 1. Layout of the field. Labels in each plot indicate the plot number and the $\mathrm{N}$ application rate, for example, "205" and "N168" mean plot 205 and N application rate of $168 \mathrm{~kg} / \mathrm{ha}$. The “市” signs indicate the plot where soil moisture sensors were installed. 
Table 1. Soil texture, irrigation status and soil moisture sensor locations in the experiment field

\begin{tabular}{|c|c|c|c|c|c|c|}
\hline Plot No. & $\%$ Clay & $\%$ Silt & $\%$ Sand & Texture & Irrigation & Data logger ID \\
\hline 101 & 2.50 & 76.50 & 21.00 & Silt Loam & Non-irr* & \\
\hline 102 & 2.50 & 75.25 & 22.25 & Silt Loam & Non-irr & Logger-1; MBS-1;IRT-1 \\
\hline 103 & 2.50 & 78.75 & 18.75 & Silt Loam & Non-irr & \\
\hline 104 & 2.50 & 77.75 & 19.75 & Slit Loam & Non-irr & \\
\hline 105 & 3.75 & 78.50 & 17.75 & Silt Loam & Non-irr & Logger-8 \\
\hline 106 & 6.25 & 76.50 & 17.25 & Silt Loam & Non-irr & \\
\hline 107 & 1.25 & 80.25 & 18.50 & Silt & Irr* & \\
\hline 108 & 1.25 & 77.00 & 21.75 & Silt Loam & Irr & \\
\hline 109 & 1.25 & 77.00 & 21.75 & Silt Loam & Irr & Logger-EM50G \\
\hline 110 & 5.00 & 82.00 & 13.00 & Silt & Irr & \\
\hline 111 & 3.75 & 79.75 & 16.50 & Silt Loam & Irr & Logger-9 \\
\hline 112 & 7.50 & 79.25 & 13.25 & Silt Loam & Irr & \\
\hline 201 & 3.75 & 74.25 & 22.00 & Silt Loam & Non-irr & \\
\hline 202 & 2.50 & 80.00 & 17.50 & Silt & Non-irr & \\
\hline 203 & 1.25 & 78.50 & 20.25 & Silt Loam & Non-irr & \\
\hline 204 & 3.75 & 77.75 & 18.50 & Silt Loam & Non-irr & \\
\hline 205 & 2.50 & 77.75 & 19.75 & Silt Loam & Non-irr & Logger-4 \\
\hline 206 & 2.50 & 75.50 & 22.00 & Silt Loam & Non-irr & \\
\hline 207 & 3.75 & 80.50 & 15.75 & Silt & Irr & \\
\hline 208 & 5.00 & 82.25 & 12.75 & Silt & Irr & \\
\hline 209 & 6.25 & 82.00 & 11.75 & Silt & Irr & Logger-10; MBS-4; IRT-4 \\
\hline 210 & 5.00 & 79.00 & 16.00 & Silt Loam & Irr & \\
\hline 211 & 3.75 & 73.00 & 23.25 & Silt Loam & Irr & \\
\hline 212 & 10.00 & 83.25 & 6.75 & Silt Loam & Irr & \\
\hline 301 & 5.00 & 78.50 & 16.50 & Silt Loam & Irr & \\
\hline 302 & 7.50 & 83.25 & 9.25 & Silt & Irr & \\
\hline 303 & 7.50 & 84.00 & 8.50 & Silt & Irr & \\
\hline 304 & 5.00 & 85.00 & 10.00 & Silt & Irr & \\
\hline 305 & 5.00 & 82.00 & 13.00 & Silt & Irr & Logger-3 \\
\hline 306 & 5.00 & 82.25 & 12.75 & Silt & Irr & \\
\hline 307 & 10.00 & 80.50 & 9.50 & Silt & Non-irr & \\
\hline 308 & 13.75 & 81.75 & 4.50 & Silt Loam & Non-irr & \\
\hline 309 & 16.25 & 78.50 & 5.25 & Silt Loam & Non-irr & \\
\hline 310 & 20.00 & 76.00 & 4.00 & Silt Loam & Non-irr & \\
\hline 311 & 15.00 & 70.75 & 14.25 & Silt Loam & Non-irr & Logger-7 \\
\hline 312 & 10.00 & 77.50 & 12.50 & Silt Loam & Non-irr & \\
\hline 401 & 8.75 & 82.75 & 8.50 & Silt & Irr & \\
\hline 402 & 16.25 & 80.50 & 3.25 & Silt Loam & Irr & Logger-2; MBS-2; IRT-2 \\
\hline 403 & 17.50 & 80.25 & 2.25 & Silt Loam & Irr & \\
\hline 404 & 17.50 & 78.25 & 4.25 & Silt Loam & Irr & \\
\hline 405 & 18.75 & 77.25 & 4.00 & Silt Loam & Irr & \\
\hline 406 & 8.75 & 78.75 & 12.50 & Silt Loam & Irr & \\
\hline 407 & 17.50 & 76.75 & 5.75 & Silt Loam & Non-irr & \\
\hline 408 & 18.75 & 78.25 & 3.00 & Silt Loam & Non-irr & \\
\hline 409 & 21.25 & 76.50 & 2.25 & Silt Loam & Non-irr & Logger-5; MBS-3; IRT-3 \\
\hline 410 & 7.50 & 89.50 & 3.00 & Silt & Non-irr & \\
\hline 411 & 21.25 & 76.25 & 2.50 & Silt Loam & Non-irr & \\
\hline 412 & 5.00 & 78.75 & 16.25 & Silt Loam & Non-irr & \\
\hline
\end{tabular}

* "Irr" stands for irrigated and "Non-irr" for Non-irrigated. 
Microprocessor-based system. The microprocessor-based system (MBS) consisted of a data logger and three Watermark 200SS matric-potential sensors (Irrometer Company, Riverside, CA USA). The data logger was based on a PIC16F819 micro-controller (Microchip Technologies, Inc., Chandler, AZ). Circuitry included a real-time clock/calendar chip for time-stamping sensor data, an alternating-current circuit for reading the soil-moisture sensors, and a non-volatile memory chip for data storage. The micro-controller was programmed to enable long-term, battery-powered operation by spending most of its time in a low-power, sleep mode. Periodically, the micro-controller would wake up and read the current time from the real-time clock. If it was time to take a measurement, power was sent to the measurement circuit, otherwise it returned to sleep mode. At one-hour intervals, the measurement circuit was enabled, the three soil-moisture sensors were read, and data were stored to the memory chip. A more detailed description of the data logger and its fabrication and operation are provided by Fisher (2007).

Infrared thermometer. The infrared thermometer (IRT) was a research prototype which included a data logger and temperature sensors (Fisher \& Kebede, 2010). The data logger consisted of a PIC16F88 micro-controller (Microchip Technologies, Inc., Chandler, AZ), real-time clock/calendar and memory chips, and circuitry for interfacing and reading sensors. Two sensor measurements were collected; air temperature, measured with an LM35 analog temperature sensor (National Semiconductor, Santa Clara, CA), and plant canopy temperature, measured with an MLX90614 IRT module (Melexis SA, Ieper, Belgium). Measurements were collected and stored to the data logger's memory chip at one-hour intervals, and were downloaded during periodic visits to a handheld computer.

\subsection{System Installation and Data Collection}

Decagon system. Decagon systems, including nine EM50R data loggers and one EM50G logger, were deployed at ten locations of the selected cotton field (Figure 1, Table 1). The locations were chosen to include a wide range of soil types. One Decagon system was installed at each of the ten locations while a MBS was installed along with the Decagon system at four locations (Table 1). To install three soil volumetric water-content sensors at each location, a bracket was made using 7.6-cm diameter PVC pipe (Figure 2). Three windows at 15, 30, and $60 \mathrm{~cm}$ from the top of the bracket were cut for inserting the sensors into the soil. A hole was drilled at the center of the crop row using a soil auger. The PVC bracket was placed into the hole with its top surface horizontally aligned with the ground surface, with the window side of the bracket installed against the wall of the hole. Then the sensors were inserted horizontally into the soil through the windows. EC-5 sensors were installed at the 15 -and $60-\mathrm{cm}$ depths while the $5 \mathrm{TM}$ sensor was installed at the $30 \mathrm{~cm}$ depth. Sensor cables were pulled out through the PVC bracket, and the hole was backfilled with soil. The data loggers were mounted on a pole made of 7.6-cm diameter PVC pipe with a height of $1.8 \mathrm{~m}$. The sensors underground were connected to the data logger by plugging sensor outputs to the data logger's inputs. A PVC coupler was used to join the underground bracket and the PVC pole above the ground (Figure 2), and was used to easily lay down the data logger to prevent damage from equipment used in field operations during the crop growing season.
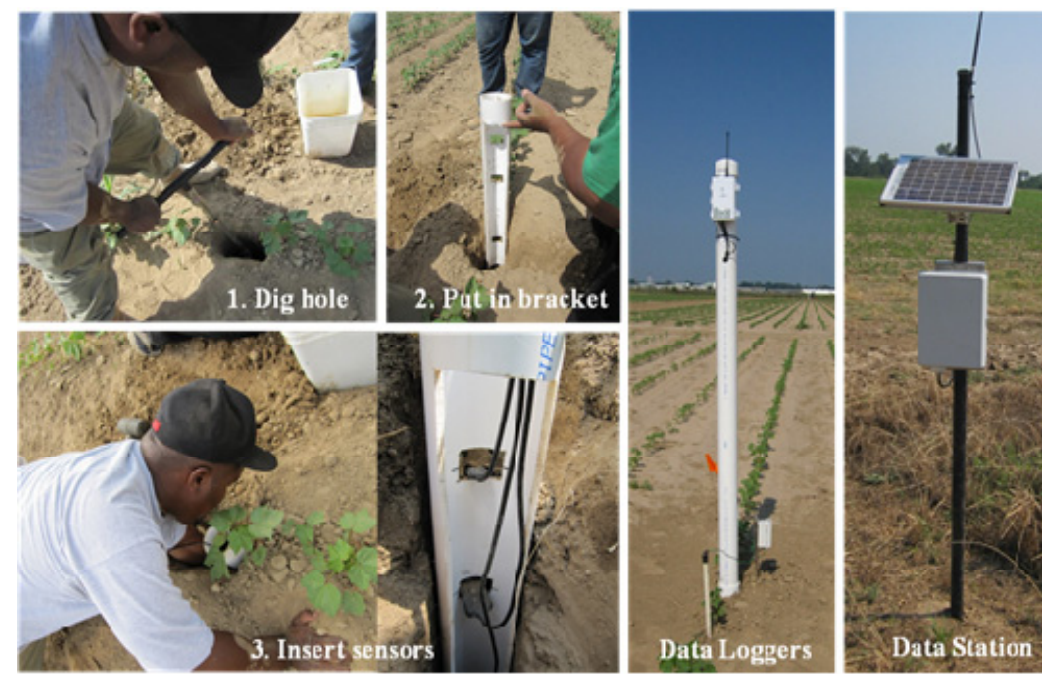

Figure 2. Installation of soil moisture sensors, data loggers, and the data station 
Data from the sensors were continuously and automatically collected at a time interval of one hour by each radio data logger and wirelessly transmitted to and recorded by the data station. Data collected by the EM50G cellular data logger were downloaded to a computer in lab after accessing the data via the internet. The data station located at the edge of the field was powered by a solar panel.

Microprocessor-based system. Watermark water-potential sensors were installed at depths of 15,30 , and $60 \mathrm{~cm}$ below the soil surface, consistent with the Decagon system. Sensors were attached to a $2.5 \mathrm{~cm}$ diameter PVC pipe and a soil auger was used to drill holes at the center of the crop row for inserting the sensors. After placing the sensors to the desired depths, the holes were backfilled and packed with soil to ensure the sensors were in good contact with the soil. The sensors were connected to a data logger, which was placed inside a weatherproof plastic enclosure attached to a wooden stake driven into the ground (Figure 2). Water potential at the three depths was measured every hour and the data were automatically stored to a memory chip in the system. Periodically throughout the growing season, each site was visited to download data from the memory chip to a portable computer. The data, in standard ASCII text format, were then returned to the office, uploaded to a desktop computer, and input to a spreadsheet for viewing and analysis.

Infrared thermometer. IRT sensors were mounted inside thick-walled PVC plastic enclosures and deployed in the field, as shown in Figure 3. Cotton rows ran east and west, and the sensors were oriented facing north, aimed at the south-facing, sunlit leaves of the crop. The sensors were installed at four sites, two in irrigated plots and two in non-irrigated plots (Table 1). Soil in this field consisted of two predominant types, silt loam and silt, with an irrigated and non-irrigated plot located in each soil. The IRT sensor measured plant canopy temperature at one hour intervals, and recorded data to a data logger.

\subsection{Field Management}

Cotton (DP 0912 B2RF) was planted on May 8, 2011. Nitrogen was variably applied to each plot in the range of 0 to $168 \mathrm{~kg} / \mathrm{ha}$ using a side knife drill on June 24,2011 . Irrigation water was applied to alternate furrows using a poly-pipe system twice during the season: $5.1 \mathrm{~cm}$ water was applied on July 6, 2011 and $7.6 \mathrm{~cm}$ on July 20, 2011. Non-irrigated plots were defoliated on September 8, 2011 and irrigated plots on September 23, 2011. Cotton was machine harvested with spindle-type picker on October 11, 2011.

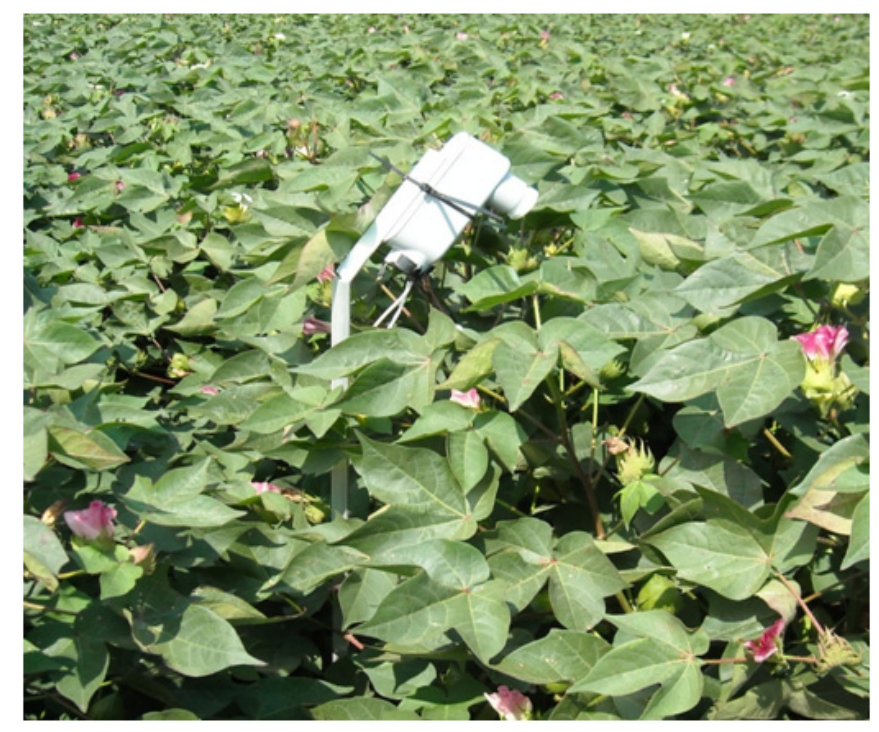

Figure 3. Infrared thermometer measuring cotton plant canopy temperature

\subsection{Data Analysis}

An ANOVA was performed with SAS software using PROC ANOVA procedure (SAS Institute Inc., Cary, NC) to evaluate effect of irrigation on yield. Monthly average of soil water content measured at three depths in each location was calculated. Soil water content and soil temperature versus time were plotted for visual comparison 
between measurement locations.

\section{Results and Discussion}

Soil moisture and soil temperature data were collected and recorded using the Decagon system and MBS during 2011 cotton growing season. In general, the sensor systems performed well in collecting data. Soil water content and temperature measured at seven locations using Decagon systems are shown in Figures 4 through 10 . The sensors responded to irrigation and rainfall events, and data collected by the systems followed trends of soil water change throughout the growing season. In the early season, from planting to 60 days after planting (DAP), sensor measurements showed soil water contents higher than in other stages of the season. Decreases in soil water content at the $15 \mathrm{~cm}$ and $30 \mathrm{~cm}$ levels were greater than at the $60 \mathrm{~cm}$ level. This could be caused by the plants using water mainly in the top layer of the soil in that period while roots were not deep enough to reach water at deeper soil levels. As plants grew and roots expanded, they absorbed more water from deeper soil, and soil water contents at greater depths decreased, as the readings from the sensors at 30 and $60 \mathrm{~cm}$ depths indicated. Soil water content showed a sharp decrease between 60 to 80 DAP, possibly due to requirements of more water for faster growth of plant biomass in the first square to early bloom stage of the cotton plants. After defoliation, plants lost leaves and used less water, and soil water contents were restored to higher levels.

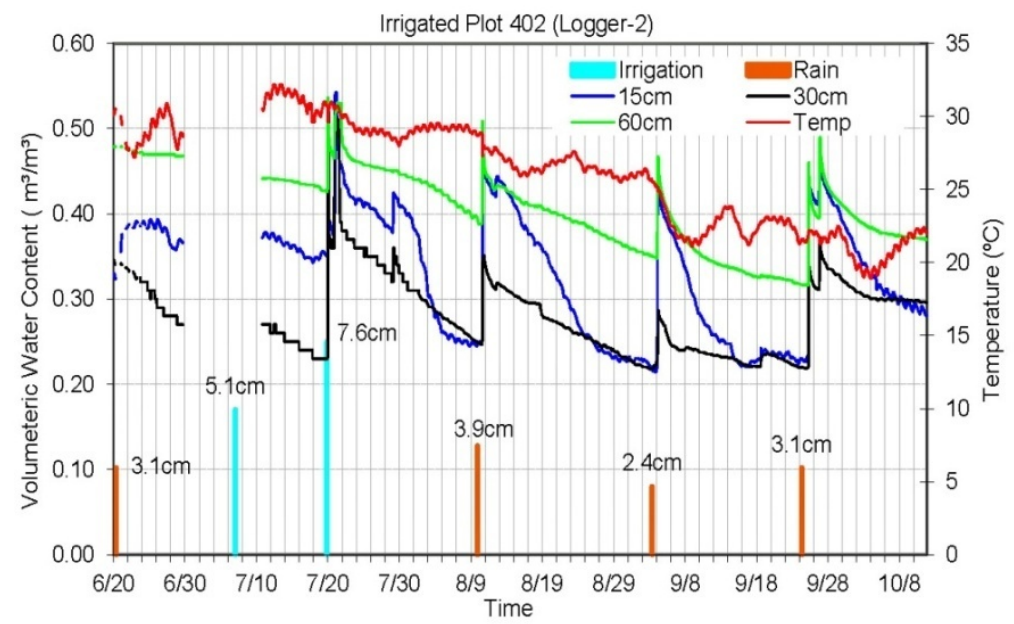

Figure 4. Soil water content and soil temperature measured in plot 402 . Missing data from $6 / 30$ to $7 / 10$ caused by new software installation in the logger

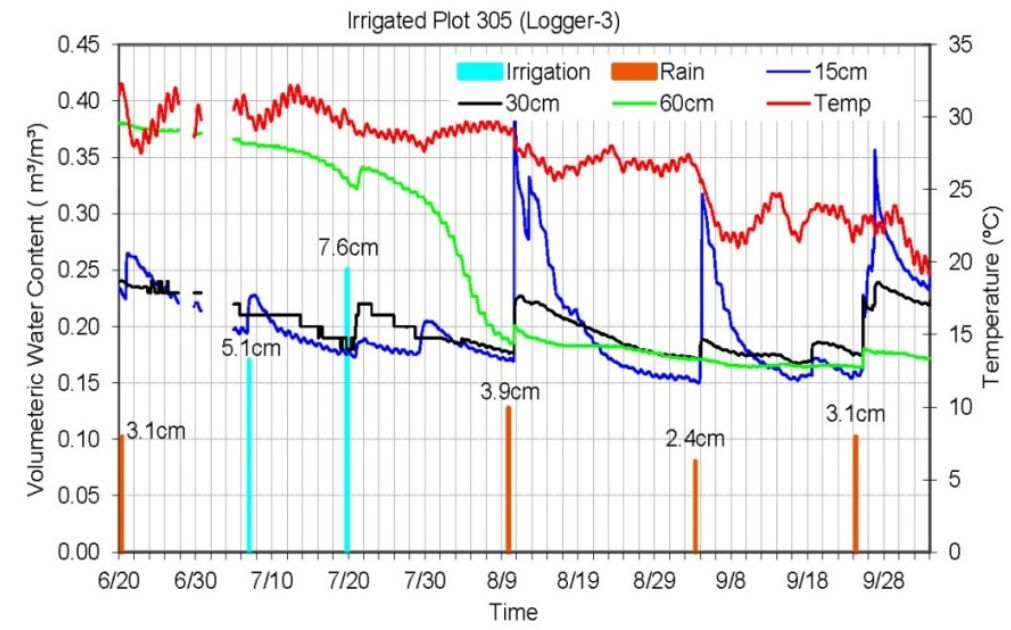

Figure 5. Soil water content and soil temperature measured by Logger-3 in plot 305 . No data were collected from $7 / 1$ to $7 / 5$ due to battery disconnection of the logger 


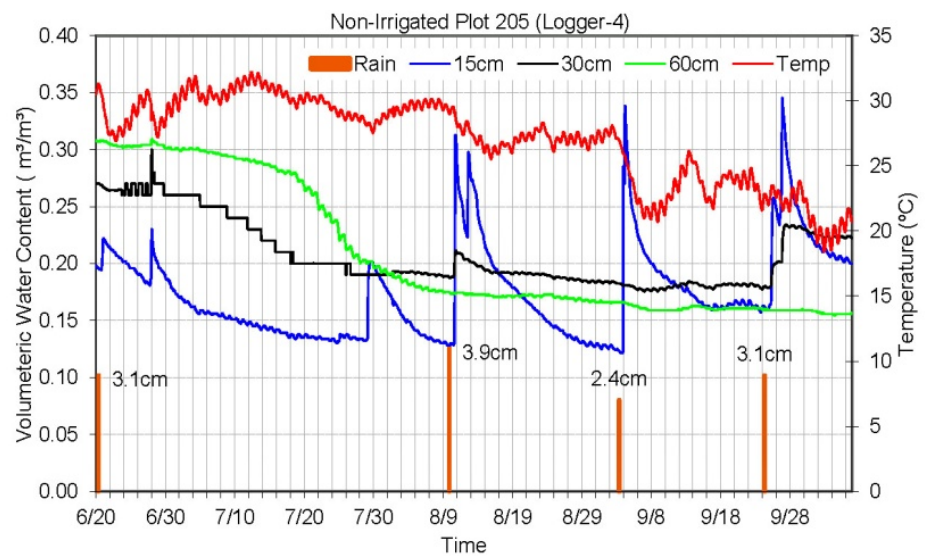

Figure 6. Soil water content and soil temperature measured by Logger-4 in plot 205

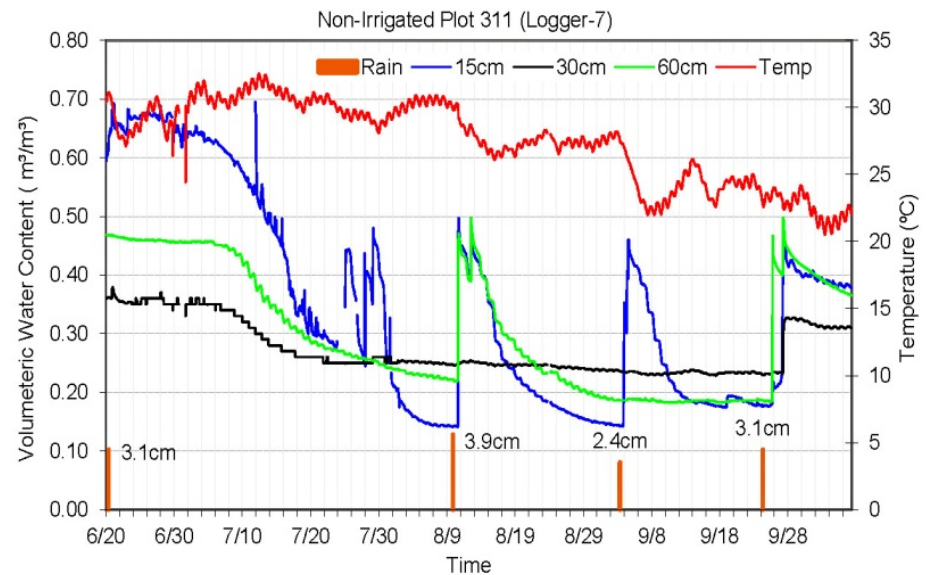

Figure 7. Soil water content and soil temperature measured by Logger-7 in plot 311

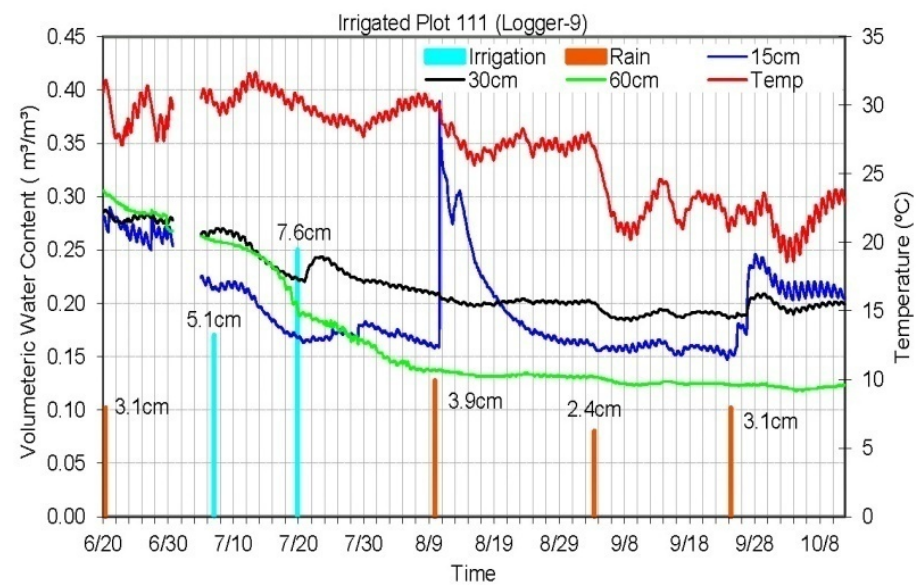

Figure 8. Soil water content and soil temperature measured by Logger-9 in plot 111 . Missing data between $7 / 2$ and $7 / 4$ due to battery disconnection in the logger 


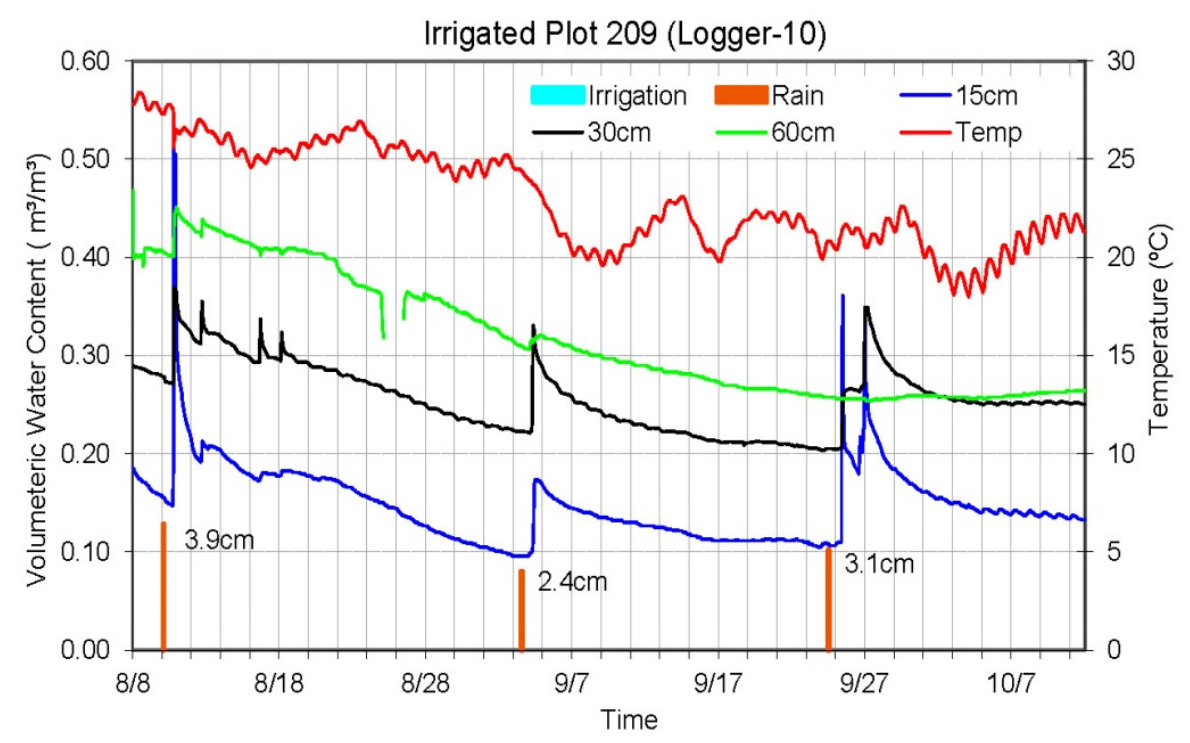

Figure 9. Soil water content and soil temperature measured by Logger-10 in plot 209

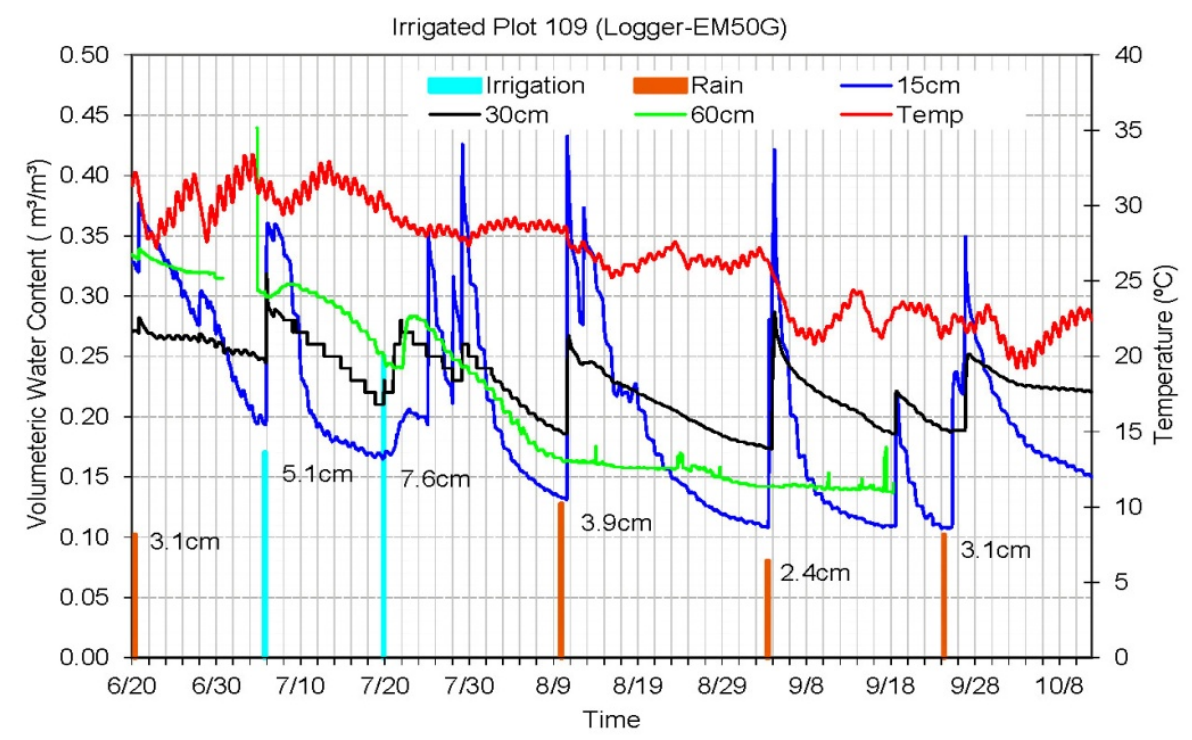

Figure 10. Soil water content and soil temperature measured by Logger-EM50G in plot 109. No data were collected after $9 / 19$ at depth of $60 \mathrm{~cm}$ due to the sensor disconnection with the logger

Monthly averages of soil water content are shown in Table 2. Due to damage to sensors and data loggers during system installation and field operations, data at the $60 \mathrm{~cm}$ depth in Logger- 1 and Logger-5, and data at the $30 \mathrm{~cm}$ depth in Logger-8 were not available. Therefore, values of soil water content with Logger-1 and Logger-5 in Table 2 were the average of measurements at depths of $15 \mathrm{~cm}$ and $30 \mathrm{~cm}$, and the values with Logger- 8 were the average at depths of $15 \mathrm{~cm}$ and $60 \mathrm{~cm}$. The values from the other seven loggers were the average at depths of $15 \mathrm{~cm}, 30 \mathrm{~cm}$, and $60 \mathrm{~cm}$. Table 2 indicates that soil water content of irrigated plots was higher than that of non-irrigated plots in July and August, but became about the same in September and October. This reflected that water applied in July raised soil moisture in irrigated plots. However, irrigation water was used by the plant in July and August. Soil water content in those plots dropped back to the same level as the non-irrigated plots after August. 
Table 2. Monthly average $\left(15,30\right.$, and $60 \mathrm{~cm}$ depth) of soil water content measured using Decagon system $\left(\mathrm{m}^{3} / \mathrm{m}^{3}\right)$

\begin{tabular}{|c|c|c|c|c|c|c|c|c|c|c|}
\hline & \multicolumn{5}{|c|}{ Irrigated } & \multicolumn{5}{|c|}{ Non-Irrigated } \\
\hline & $\log -2$ & $\log -3$ & Log-9 & Log-10 & EM-50G & Log-1* & $\log -4$ & $\log -5^{*}$ & $\log -7$ & $\log -8 * *$ \\
\hline June & 0.38 & 0.28 & 0.28 & NA & 0.30 & 0.24 & 0.26 & 0.47 & 0.49 & 0.27 \\
\hline July & 0.38 & 0.25 & 0.22 & 0.39 & 0.25 & 0.20 & 0.21 & 0.36 & 0.37 & 0.18 \\
\hline Aug & 0.33 & 0.20 & 0.18 & 0.28 & 0.19 & 0.24 & 0.18 & 0.27 & 0.25 & 0.13 \\
\hline Sep & 0.30 & 0.18 & 0.16 & 0.22 & 0.17 & 0.20 & 0.18 & 0.24 & 0.24 & 0.12 \\
\hline Oct & 0.33 & 0.21 & 0.18 & 0.22 & $0.20^{\vee}$ & 0.22 & 0.20 & 0.24 & 0.36 & 0.13 \\
\hline
\end{tabular}

Notes:

1. *Average of 15 and $30 \mathrm{~cm}$ depth.

2. **Average of 15 and $60 \mathrm{~cm}$ depth. Due to damage of sensor and data logger in system installation and field operation, data at $60 \mathrm{~cm}$ depth in Logger- 1 and Logger-5, and data at $30 \mathrm{~cm}$ depth in Logger- 8 were not available.

3. ${ }^{\vee}$ Average of 15 and $30 \mathrm{~cm}$ depth.

Soil water contents measured in plot 402 (Logger-2), 409 (Logger-5), and 311 (Logger-7) were higher than other plots (Table 2, Figures 4 and 7). This could be a function of the soil properties in the plots (Table 1). Clay contents in plots 402,409 , and 311 were $16.25 \%, 21.25 \%$, and $15.00 \%$, respectively, which was much higher than in other plots where soil water content was monitored. Higher clay contents in those three plots resulted in higher water-holding capacities (Saxton, Rawls, Romberger, \& Papendick, 1986).

Hourly data showing Watermark soil-water potential measurements and Decagon volumetric water-content measurements are shown in Figure 11. The numerical data from the two different sensor types could not be related directly due to the different physical soil parameters measured. They could, however, be compared qualitatively by observing the general trends in the measurements over time. At each depth, the corresponding sensors showed consistent behaviors, reacting to the changing conditions at each depth in the soil profile. Lower (more negative) soil-water potential readings at the 15 and $60 \mathrm{~cm}$ depths indicated that soil water was less available than at the $30 \mathrm{~cm}$ depth, but steadily changing values suggested that the plants were able to access the moisture at all levels. Around August 8, behavior of the $30 \mathrm{~cm}$ sensors suggested that roots at this depth may have begun to reduce water-use: water-potential readings began to decrease more rapidly, while water-content readings stopped decreasing.

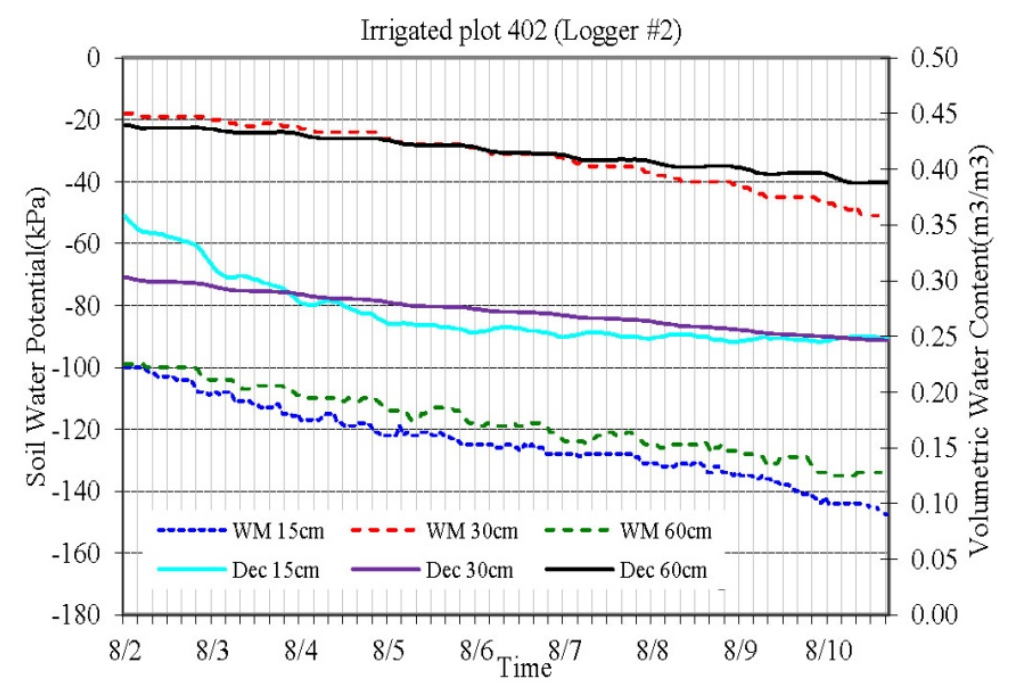

Figure 11. Comparing soil water content measured by Decagon system using Decagon sensor (referred to as Dec.) with soil water potential measured by the microprocessor-based system using Watermark sensor (referred to as 
The Decagon system was programmed to use a calibration algorithm provided by the manufacturer. Since this was a new measurement system, the intent was to install the sensors and ensure that the data loggers and wireless and cellular communications operated properly. No sensor recalibration work was done to verify or modify the manufacturer's calibration equations for local soil characteristics. The system might need to be recalibrated for local conditions since different soil properties could have different effects on the sensor's response to soil water content.

Hourly canopy-temperature measurements during a five-day period in August-September 2011 are shown in Figure 12. Canopy temperatures in the non-irrigated plots were 2-4 C higher than in the irrigated plots during the peak time of the day.

Soil temperature sensors in the Decagon systems performed well in monitoring soil temperature at the $30 \mathrm{~cm}$ depth (Figures 4 through 10). Soil temperature variation showed that plant canopy had a noticeable effect on soil temperature. Soil temperature decreased after the plant canopy was well developed, and increased after defoliation of the cotton plants. Data also demonstrated that soil water content had an effect on soil temperature, with soil temperature increasing as soil water content decreased.

The ANOVA test revealed that seed cotton yield in plots differed significantly as a function of irrigation $(\mathrm{F}(1,45)$ $=17.02, p=0.0002)$. Mean of the yield in non-irrigated plots was $2975 \mathrm{~kg} / \mathrm{ha}(\mathrm{SD}=309 \mathrm{~kg} / \mathrm{ha})$ and $3399 \mathrm{~kg} / \mathrm{ha}$ $(\mathrm{SD}=391 \mathrm{~kg} / \mathrm{ha})$ in irrigated plots. Supplemental irrigation in this study, therefore, increased yield by $14.2 \%$.

A few issues affecting the performance of the monitoring system were observed during field operation of the Decagon wireless systems: 1) actions of laying down the data logger, which was mounted on a PVC pole, on the ground during chemical and fertilizer applicationsoften resulted in the batteries inside the data logger becoming loose and losing connection, causing the data logger to stop collecting data; 2) an unprotected sensor cable was damaged by animals in the field; 3 ) sensors could be damaged if they were inserted into hard soil during the installation process; and 4) data loggers were occasionally knocked down by field equipment such as sprayers. Attention must be given to resolve these issues for successful application of the wireless system in agricultural fields.

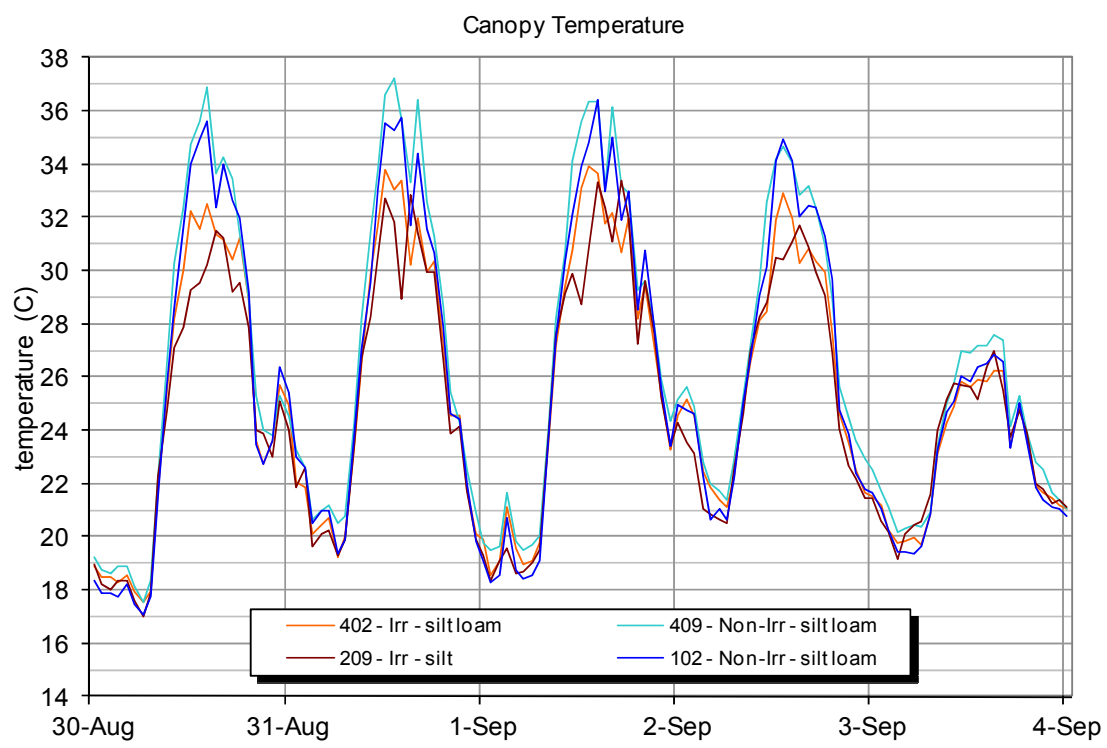

Figure 12. Canopy temperatures measured using the Infrared Thermometer. Plots 402 and 209 are irrigated. Plots 409 and 102 are non-irrigated

\section{Conclusions}

For studies on irrigation scheduling, a wireless sensor network system and a microprocessor-based system were deployed to measure soil water and soil temperature in a cotton field. Plant canopy temperature was also measured using infrared thermometer sensors. Procedures for installation and maintenance of the soil water measurement systems were developed and evaluated. Results indicated that the soil water sensors were able to monitor the soil water status, and that measurements recorded by the systems reflected general trends of soil water change during 
the growing season. Soil water content decreased at a higher rate in $15 \mathrm{~cm}$ and $30 \mathrm{~cm}$ depth than in $60 \mathrm{~cm}$ depth before 60 DAP. A sharp decrease of soil water content in $60 \mathrm{~cm}$ depth was observed from 60 to 80 DAP. Sensor measurements responded to the effects of soil texture on available water capacity. Canopy temperature of non-irrigated plants is $2-4 \mathrm{C}$ higher than that of the irrigated plants during the peak time of day. Supplemental irrigation increased yield by $14.2 \%$ in this study. System installation and maintenance procedures developed worked well in general, however, some installation and operational issues need to be resolved for wider field operation and user acceptance. Results reported in this article were obtained in the first year of the study. This research will be continued.

\section{Acknowledgements}

Appreciation is extended to Cotton Incorporated (Cary, NC, USA) for their financial support of this project.

\section{Disclaimer}

Mention of a commercial product is solely for the purpose of providing specific information and should not be construed as a product endorsement by the authors or the institutions with which the authors are affiliated.

\section{References}

Evett, S. R., Tolk, J. A., \& Howell, T. A. (2006). Soil profile water content determination: sensor accuracy, axial response, calibration, temperature dependence, and precision. Vadose Zone Journal, 5, 894-907. http://dx.doi.org/10.2136/vzj2005.0149

Fisher, D. K. (2007). Automated collection of soil-moisture data with a low-cost microcontroller circuit. Applied Engineering in Agriculture, 23(4), 493-500.

Fisher, D. K., \& Kebede, H. (2010). A low-cost microcontroller-based system to monitor crop temperature and water status. Computers and Electronics in Agriculture, 74(1), 168-173. http://dx.doi.org/10.1016/j.compag.2010.07.006

Harms, T. E. (2005). Soil moisture based web to wireless center pivot operation. 2005 Pacific Northwest section meeting. ASABE Paper No. PNW05-1003. St. Joseph, Mich.: ASABE.

Kim, Y., Evans, R. G., \& Iversen, W. M. (2009). Evaluation of closed-loop site-specific irrigation with wireless sensor network. Journal of Irrigation and Drainage Engineering, 135(1), 25-31. http://dx.doi.org/10.1061/(ASCE)0733-9437(2009)135:1(25)

King, B. A., Wall, R. W., \& Wall, L. R. (2005). Distributed control and data acquisition system for closed-loop site-specific irrigation management with center pivots. Applied Engineering in Agriculture, 21(5), 871-878.

Kitchen, N. R. (2008). Emerging technologies for real-time and integrated agriculture decision. Computers and Electronics in Agriculture, 61(1), 1-3. http://dx.doi.org/10.1016/j.compag.2007.06.007

Lea-Cox, J. D., Ristvey, A. G., Ross, D. S., \& Kantor, G. F. (2009). Deployment of wireless sensor networks for irrigation and nutrient management in nursery and greenhouse operations. SNA Research Conference Vol. 54.

Leib, B. G., Jabro, J. D., \& Matthews, G. R. (2003). Field evaluation and performance comparison of soil moisture sensors. Soil Science, 168(6), 396-408. http://dx.doi.org/10.1097/01.ss.0000075285.87447.86

Moody, F. H., Wilkerson, J. B., Hart, W. E., \& Sewell, N. D. (2004). A digital event recorder for mapping field operations. Applied Engineering in Agriculture, 20(1), 119-128.

Noordin, K. A., Onn, C. C., \& Ismail, M. F. (2006). A low-cost microcontroller-based weather monitoring system. CMU Journal, 5(1), 33-39.

O'Shaughnessy, S. Y., \& Evett, S. R. (2010). Developing wireless sensor networks for monitoring crop canopy temperature using a moving sprinkler system as a platform. Applied Engineering in Agriculture, 26(2), 331-341.

Pierce, F. J., \& Elliott, T. V. (2008). Regional and on-farm wireless sensor networks for agricultural systems in Eastern Washington. Computers and Electronics in Agriculture, 61(1), 32-43. http://dx.doi.org/10.1016/j.compag.2007.05.007

Saxton, K. E., Rawls, W. J., Romberger, J. S., \& Papendick, R. I. (1986). Estimating generalized soil-water characteristics from texture. Soil Science Society of America Journal, 50(4), 1031-1036. http://dx.doi.org/10.2136/sssaj1986.03615995005000040039x 
Vellidis, G., Tucker, M., Perry, C., Kvien, C., \& Bednarz, C. (2008). A real-time wireless smart sensor array for scheduling irrigation. Computers and Electronics in Agriculture, 61, 44-50. http://dx.doi.org/10.1016/j.compag.2007.05.009

Wang, N., Zhang, N., \& Wang, M. (2006). Wireless sensors in agriculture and food industry-Recent development and future perspective. Computers and Electronics in Agriculture, 50(1), 1-14. http://dx.doi.org/10.1016/j.compag.2005.09.003

Yoder, R. E., Johnson, D. L., Wilkerson, J. B., \& Yoder, D. C. (1997). Soil water sensor performance. Applied Engineering in Agriculture, 14(2), 121-133. 